\title{
Prevalence of Bullying among LGBT Students in Nueva Ecija
}

\author{
Kim Edward S. Santos, Crisanto D. De Jesus \\ Nueva Ecija University of Science and Technology, Cabanatuan City, Philippines \\ Email:kimnyte@gmail.com,crisddejsus@gmail.com
}

How to cite this paper: Santos, K.E.S. and De Jesus, C.D. (2020) Prevalence of Bullying among LGBT Students in Nueva Ecija. Open Access Library Journal, 7: e6066. https://doi.org/10.4236/oalib.1106066

Received: January 11, 2020

Accepted: January 31, 2020

Published: February 3, 2020

Copyright $\odot 2020$ by author(s) and Open Access Library Inc.

This work is licensed under the Creative Commons Attribution International License (CC BY 4.0).

http://creativecommons.org/licenses/by/4.0/

\begin{abstract}
In general, school bullying, and LGBT student harassment in particular, have increasingly gained national attention as a serious issue that needs to be resolved. This paper described the types and forms of bullying that LGBT students have experienced in terms of: Verbal or Written, Physical, Relational or Social, and Cyber; the negative impacts of bullying LGBT students; and, the solution or suggestions of LGBT students to minimize bullying. The study used descriptive method and utilized Likert-scale type questionnaire. A total of 152 college students ( 90 from private schools and 62 from state universities and colleges) in Nueva Ecija were involved in this study. They were composed of 98 gays, 22 lesbians, and 32 self-confessed bisexuals. Based on the results of this study, it was concluded that verbal/written bullying was the most prevalent type of bullying that LGBT students had experienced in their school. This is in the forms of persistent teasing, threatening, intimidating, and name calling. Likewise, bullying had caused negative impacts on them especially on the state of their emotions and feelings. They feel anxious, threatened, concealed feelings and unable to trust others. Other types of bullying (physical, social/relational, and cyber) were only sometimes experienced by the LGBT students but some of its forms were still occurred in their school like restraining, showing subtle but negative languages, and embarrassing and humiliating online. It was further concluded that the prevalence of bullying among LGBT students can be minimized through the help of those who are experiencing it with the help of their school community (parents, teachers, administrators and staff).
\end{abstract}

\section{Subject Areas}

Sociology

\section{Keywords}

Bullying, Lesbian, Gay, Cyber Bullying, Verbal Bullying, LGBT, Gender 


\section{Introduction}

In general, school bullying, and LGBT student harassment in particular, have increasingly gained national attention as a serious issue that needs to be resolved. As discussed in [1], the political landscape and social environment change over time, LGBT youth may also have experiences linked to bullying and harassment. Further discussion in [2], found that schools breach the civil rights of students suffering from discrimination on the grounds of their sexual orientation if the abuse creates a hostile environment and is not handled meaningfully by school staff.

The results in [3] in their review of studies found that LGBT youth, particularly gender non-conforming children, are three times more likely to experience adverse punitive action by school administrators relative to their non-LGBT peers, and LGBT youth are substantially distrustful of school administrators and do not think school officials are doing enough to promote a safe and welcoming school environment. As concluded in [4], LGBT pupils in schools where principals do not deal with the use of homophobic and transphobic words often and frequently witness their condoned contempt.

The problem can be attributed to a series of highly linked, high-profile cases that ended in tragedy for teenagers who were assaulted because of their real or perceived sexual orientation or, in a closely related manner, because they did not comply with rigidly controlled gender expectations [5]. As with sexual minority Philippine men and related studies on sexual minority women in other parts of the world, [6] discussed that being gay or bisexual was correlated with the Philippines' elevated suicide ideation and attempt.

It was found in [7] that there is a sluggish inclusive living climate of students from Filipino LGBT who lack legal protection; suffer from mental health issues, opposed to religion. Thus, [8] recommended that teachers need to be aware of their own biases to help LGBT students and consider how their own views might influence how they talk to students. In reaction to the increased risk of being harassed and becoming suicide among sexual minority teenagers, school staff should develop anti-bullying and anti-homophobia policies. In reaction to the increased risk of being harassed and becoming suicide among sexual minority teenagers, [9] further recommended that school staff should develop anti-bullying and anti-homophobia policies.

\section{Conceptual Framework}

Concluded in [10], their study entitled Bullied back in the closet: Disengagement of LGBT employees facing workplace bullying that the bullying process is mentally and physiologically damaging to people.

As found in [11], 90\% of LGBT youth were verbally or physically abused or attacked due to their perceived or actual identity, class, sexual orientation, or gender expression.

According to the study entitled "LGBT Oppression", [12] concluded that LGBT youth is a group at risk of violence in and through classrooms in schools. 


\section{Objectives of the Study}

The study described the types and forms of bullying that LGBT students have experienced in terms of: Verbal or Written, Physical, Relational or Social, and Cyber; the negative impacts of bullying LGBT students; and, the solution or suggestions of LGBT students to minimize bullying.

\section{Methodology}

The study used descriptive method as it describes the present condition. Descriptive research involves defining the characteristics of a particular occurrence based on an empirical analysis, or investigating the association between two or more phenomena [13]. A total 152 college students (90 from private schools and 62 from state universities and colleges) in Nueva Ecija were involved in this study. They were composed 98 gays, 22 lesbians, and 32 self-confessed bisexuals. The researchers utilized Likert-scale type questionnaire [14] and analyzed it through statistical data treatment such as ranking, mean and weighted mean.

\section{Results and Discussion}

Table 1 presents the mean ratings on the types/forms of bullying that the LGBT students have experienced. Bullying has five types: verbal/written, physical, social/relational, and cyber. Each type has different forms.

Verbal/written Bullying. In the table presented, the LGBT students scored a mean of 4.26 with a verbal interpretation of frequently experienced. All the forms of verbal/written bullying were interpreted as frequently experienced which implies that this type of bullying was happened to the LGBT students. Among the forms of verbal/written bullying, items 3, 1, and 5 got highest means respectively. This means that LGBT frequently experienced persistent teasing ( $X$ $=4.87)$, name-calling $(X=4.36)$, and receiving cruel jokes, remarks, and comments $(X=4.35)$.

Physical Bullying. LGBT students scored physical bullying with a mean rating of 1.66 and verbal interpretation of never experienced. However, there were two items that have highlighted this type of bullying. LGBT students occasionally/sometimes experienced restraining $(X=2.63)$ and extortion/stealing $(X=$ 1.90). The results imply that though physical type of bullying never occurred in general among the LGBT students that are still some of its form happening and experienced by other students.

Social/Relational Bullying. In the social/relational type of bullying, LGBT students scored a mean rating of 2.14 which means that they almost never experienced this type of bullying. Item 4 got highest mean of 3.78 which means that LGBT students almost every time they experienced their peers showed subtle but negative body language to them. On the other hand, item 2 got the lowest mean of 1.02 which means that students never experienced destroying or manipulating relationships-stealing a friend.

Cyber Bullying. In the table presented, cyber bullying got a mean rating of 
Table 1. Types/forms of bullying that LGBT students have experienced.

\begin{tabular}{|c|c|c|}
\hline TYPES/FORMS OF BULLYING & MEAN & VI \\
\hline \multicolumn{3}{|l|}{ VERBAL OR WRITTEN } \\
\hline 1. Name-calling & 4.36 & Frequently experienced \\
\hline 2. Threatening and intimidating & 3.44 & Frequently experienced \\
\hline 3. Persistent teasing & 4.87 & Frequently experienced \\
\hline 4. Embarrassing and insulting & 4.30 & Frequently experienced \\
\hline 5. Receiving cruel jokes, remarks, comments & 4.35 & Frequently experienced \\
\hline Average weighted mean & 4.26 & Frequently Experienced \\
\hline \multicolumn{3}{|l|}{ PHYSICAL } \\
\hline 1. Hitting, slapping (using other objects) & 1.34 & Never experienced \\
\hline 2. Extortion, stealing & 1.90 & Occasionally or Sometimes \\
\hline 3. Damaging/destroying or defacing a personal belonging & 1.28 & Never experienced \\
\hline 4. Elbowing, kicking, shoving, or headlocks & 1.15 & Never experienced \\
\hline 5. Restraining & 2.63 & Occasionally or Sometimes \\
\hline Average weighted mean & 1.66 & Never experience \\
\hline \multicolumn{3}{|l|}{ RELATIONAL/SOCIAL } \\
\hline 1. Passing hate petitions and mean notes/text messages/e-mails & 1.98 & Almost never \\
\hline 2. Destroy or manipulate relationships-stealing a friend & 1.15 & Never Experienced \\
\hline 3. Experiencing group expulsion/separation & 2.68 & Occasionally or Sometimes \\
\hline 4. Showing subtle but negative body language and gestures & 3.78 & Almost every time \\
\hline 5. Circulating rumors & 2.23 & Never experienced \\
\hline Average weighted mean & 2.14 & Almost never \\
\hline \multicolumn{3}{|l|}{$C Y B E R$} \\
\hline 1. Embarrassing or humiliating you through text messages, e-mails, or chats, & 1.76 & Never experienced \\
\hline 2. Impersonating online to make you look bad or to destroy your reputation & 1.19 & Never experienced \\
\hline 3. Receiving hateful, malicious, derogatory and/or cruel/mean jokes and information & 1.67 & Never experienced \\
\hline 4. Spreading rumors, gossips and lies online or by means of electronic or social media & 1.34 & Never experienced \\
\hline 5. Threatening or intimidating you online & 1.25 & Never experienced \\
\hline Average weighted mean & 1.44 & Never experienced \\
\hline
\end{tabular}

Legend: 4.24 - 5.00: Frequently experienced; 3.43 - 4.23: Almost every time; 2.62 - 3.42: Occasionally or Sometimes; 1.81 - 2.61: Almost never; 1.00 - 1.80: Never experience.

1.44 with a verbal interpretation of never experienced. This means that LGBT students never experienced cyber bullying in the forms of embarrassing or humiliating, receiving hateful or malicious notes/jokes, and impersonating online, using chats or text messages.

Table 2 shows the summary of mean rating results of the types of bullying. Based from the results, verbal/written type of bullying got the highest mean of 4.26. This means that LGBT students frequently experienced this among the 
other types of bullying. It was followed by social/relational bullying $(X=2.14)$ that the students almost never experienced this type of bullying. On the other hand, LGBT students never experienced physical $(X=1.66)$ and cyber $(X=1.44)$ types of bullying.

Table 3 shows the negative impacts of bullying on the LGBT students.

Based on the results, LGBT students agreed $(X=2.86)$ that there are negative impacts of bullying on them. Statements $1(X=3.68), 7(X=3.60)$, and $3(X=$ 3.52 ) got the highest means, respectively, with verbal interpretations of strongly agree. LGBT students feel anxious every time others teased me for being gay/lesbian. They cannot show their true feelings because others do not listen to them. And in addition, they feel threatened. The results imply that LGBT students' ability to trust others is being affected.

On the other hand, statement 10 got the lowest mean of 1.88 and with verbal interpretation of strongly disagree. This shows that LGBT students strongly disagreed that they cannot join in their school activities. This implies that being LGBT students is not a hindrance for them to participate in their school activities.

Table 4 shows the solutions or suggestions of LGBT Students to minimize bullying. Based on the results, LGBT students strongly agreed that there are solutions that can be suggested to minimize bullying incidents. The top three

Table 2. Summary of mean rating results of the types of bullying.

\begin{tabular}{lccc}
\hline \multicolumn{1}{c}{ TYPES OF BULLYING } & MEAN & Verbal Interpretation & RANK \\
\hline 1. Verbal/Written & 4.26 & Frequently experienced & 1 \\
2. Social/Relational & 2.14 & Almost never & 2 \\
3. Physical & 1.66 & Never experienced & 3 \\
4. Cyber & 1.44 & Never experienced & 4 \\
\hline
\end{tabular}

Table 3. Negative impacts of bullying LGBT students.

\begin{tabular}{lcc}
\hline \multicolumn{1}{c}{ Statements } & WM & VI \\
\hline 1. I feel anxious every time others teased me for being gay/lesbian. & 3.68 & Strongly Agree \\
2. I lose confidence when I am in front of people. & 3.21 & Agree \\
3. I feel threatened. & 3.52 & Strongly Agree \\
4. I skip school to get away from the people who bully me. & 2.39 & Disagree \\
5. I have thoughts of committing suicide to escape from bullying. & 2.40 & Disagree \\
6. I feel unsafe in our school. & 2.25 & Disagree \\
7. I cannot show my true feelings because they do not listen to me. & 3.60 & Strongly Agree \\
8. I find it hard to establish relationship with my peers. & 3.22 & Agree \\
9. I feel I do not belong in our class. & 2.40 & Disagree \\
10. I cannot join to our school activities. & 1.88 & Strongly Disagree \\
& 2.86 & Agree \\
\hline
\end{tabular}

Legend: 1.00 - 1.74: Strongly Disagree; 1.75 - 2.49: Disagree; 2.50 - 3.25: Agree; 3.26 - 4.00: Strongly Agree. 
Table 4. The solutions or suggestions of LGBT students to minimize bullying.

\begin{tabular}{|c|c|c|}
\hline SOLUTION OR SUGGESTIONS & WM & VI \\
\hline $\begin{array}{l}\text { 1. Working with student councils to have programs on respect, } \\
\text { school safety and anti-bullying }\end{array}$ & 2.69 & Agree \\
\hline 2. Organize a school organization that will help LGBT students & 3.02 & Agree \\
\hline $\begin{array}{l}\text { 3. Ask school personnel to have a discussion at an assembly or an } \\
\text { after-school activity about gay/lesbian bullying }\end{array}$ & 3.66 & Strongly Agree \\
\hline $\begin{array}{l}\text { 4. School should present bullying prevention activities and } \\
\text { programs at your school. }\end{array}$ & 3.43 & Strongly Agree \\
\hline $\begin{array}{l}\text { 5. Do encourage anyone who's being bullied to tell a teacher, } \\
\text { counselor, coach, nurse, or his or her parents or guardians }\end{array}$ & 3.79 & Strongly Agree \\
\hline $\begin{array}{l}\text { 6. Pairing a student with a specific adult advocate/mentor for } \\
\text { regular support }\end{array}$ & 2.98 & Agree \\
\hline $\begin{array}{l}\text { 7. Teaching students what to do when they witness a bullying } \\
\text { incident }\end{array}$ & 3.28 & Strongly Agree \\
\hline $\begin{array}{l}\text { 8. Conduct capacity building for teachers, staff, and student in } \\
\text { handling bullying case }\end{array}$ & 3.57 & Strongly Agree \\
\hline 9. Involving students in establishing rules against bullying & 3.86 & Strongly Agree \\
\hline $\begin{array}{l}\text { 10. Maintain the school as a safe environment for learning for all } \\
\text { the students }\end{array}$ & 3.27 & Strongly Agree \\
\hline AVERAGE WEIGHTED MEAN & 3.36 & Strongly Agree \\
\hline
\end{tabular}

Legend: 1.00 - 1.74: Strongly Disagree; 1.75 - 2.49: Disagree; 2.50 - 3.25: Agree; 3.26 - 4.00: Strongly Agree.

suggestions based on their mean ratings were: Involving students in establishing rules against bullying $(X=3.86)$; do encourage anyone who's being bullied to tell a teacher, counselor, coach, nurse, or his or her parents or guardians $(X=3.79)$; and ask school personnel to have a discussion at an assembly or an after-school activity about gay/lesbian bullying $(X=3.66)$. These results imply that when minimizing incidents of bullying in school, rules are very important especially when students are involved in making these rules. LGBT students need encouragement to speak for themselves when they experience bullying in the school.

Moreover, LGBT students also agreed that other solutions were pairing a student with a specific adult advocate/mentor for regular support $(X=2.98)$ and Working with student councils to have programs on respect, school safety and anti-bullying $(X=2.69)$. These imply collaboration of teachers, students and staff is also important in minimizing bullying incidents.

\section{Conclusions}

Based on the results of this study, it was concluded that verbal/written bullying was the most prevalent type of bullying that LGBT students had experienced in their school. This is in the forms of persistent teasing, threatening, intimidating, and name calling. Likewise, bullying had caused negative impacts on them especially on the state of their emotions and feelings. They feel anxious, threatened, concealed feelings and unable to trust others. Other types of bullying (physical, 
social/relational, and cyber) were only sometimes experienced by the LGBT students but some of its forms still occurred in their school like restraining, showing subtle but negative languages, and embarrassing and humiliating online.

It was further concluded that the prevalence of bullying among LGBT students can be minimized through the help of those who are experiencing it with the help of their school community (parents, teachers, administrators and staff). Moreover, LGBT students should be included in establishing firm school rules against bullying. They should also be encouraged to speak for themselves and to tell school authorities about their bullying experiences. Similarly, student programs and activities should also advocate respect, school safety, and open discussions among LGBT student populations of the schools.

\section{Conflicts of Interest}

The authors declare no conflicts of interest regarding the publication of this paper.

\section{References}

[1] Kosciw, J.G., Bartkiewicz, M. and Greytak, E.A. (2012) Promising Strategies for Prevention of the Bullying of Lesbian, Gay, Bisexual, and Transgender Youth. The Prevention Researcher, 19, 10-14. https://doi.org/10.1037/e534992013-004

[2] Hinduja, S. and Patchin, J.W. (2011) Cyberbullying Research Summary: Bullying, Cyberbullying, and Sexual Orientation. Cyberbullying Research Center. http://cyberbullying.org/cyberbullying sexual orientation fact sheet.pdf https://doi.org/10.1080/13811118.2010.494133

[3] Mitchum, P. and Moodie-Mills, A.C. (2014) Beyond Bullying: How Hostile School Climate Perpetuates the School-to-Prison Pipeline for LGBT Youth. Center for American Progress, Washington DC.

[4] Wright, T.E. and Smith, N. (2013) Bullying of LGBT Youth and School Climate for LGBT Educators. GEMS (Gender, Education, Music, and Society), The On-Line Journal of GRIME (Gender Research in Music Education), 6.

[5] Culhane, J.G. (2011) More than the Victims: A Population-Based, Public Health Approach to Bullying of LGBT Youth. Public Health Approach to Bullying of LGBT Youth. Rutgers Law Record, 38, 2010-2011.

[6] Manalastas, E.J.D. and Torre, B.A. (2013) Social Psychological Aspects of Advocating LGBT Human Rights in the Philippines. Gender and Justice Action Research Program, Institute of Human Rights, University of the Philippines Law Center.

[7] Tang, X. and Poudel, A.N. (2018) Exploring Challenges and Problems Faced by LGBT Students in Philippines: A Qualitative Study. Journal of Public Health Policy and Planning, 2, 9-17.

[8] Bratsis, M.E. (2015) Supporting Bullied LGBT Students. The Science Teacher, 82, 12. https://doi.org/10.2505/4/tst15 $08209 \quad 12$

[9] Mueller, A.S., James, W., Abrutyn, S. and Levin, M.L. (2015) Suicide Ideation and Bullying among US Adolescents: Examining the Intersections of Sexual Orientation, Gender, and Race/Ethnicity. American Journal of Public Health, 105, 980-985. https://doi.org/10.2105/AJPH.2014.302391

[10] Hollis, L.P. and McCalla, S.A. (2013) Bullied Back in the Closet: Disengagement of 
LGBT Employees Facing Workplace Bullying. Journal of Psychological Issues in Organizational Culture, 4, 6-16. https://doi.org/10.1002/jpoc.21109

[11] Espelage, D.L. and Swearer Napolitano, S.M. (2008) Addressing Research Gaps in the Intersection between Homophobia and Bullying.

[12] Watson, S. and Miller, T. (2012) LGBT Oppression. Multicultural Education, 19, $2-7$.

[13] Creswell, J.W. (2002) Educational Research: Planning, Conducting, and Evaluating Quantitative. Prentice Hall, Upper Saddle River, NJ, 146-166.

[14] Vagias, W.M. (2006) Likert-Type Scale Response Anchors. Clemson International Institute for Tourism \& Research Development, Department of Parks, Recreation and Tourism Management, Clemson University. 